\title{
Padaczka u pacjenta z mnogimi naczyniakami jamistymi - opis przypadku
}

\author{
The Case of epilepsy in a patient withmultiple cavernous hemangiomas
}

\author{
Anna Szyszko-Szwed (iD \\ Klinika Neurologii i Rehabilitacji Dziecięcej, Uniwersytet Medyczny im. Ludwika Zamenhoffa Waszyngtona 17, 15-274 Białystok \\ DOI:10.20966/chn.2020.59.476
}

\section{STRESZCZENIE}

Naczyniaki jamiste(CM) to łagodne zmiany o typie hamartoma. Rozpowszechnienie ich w populacji ogólnej waha się 0,4-0,8\% i stanowi ok. $15 \%$ wszystkich wad naczyniowych. W częstości występowania szacuje się, że są drugie w kolejności po rozwojowych malformacjach żylnych. Większość ma charakter zmian pojedynczych. W badaniu tomografii komputerowej (CT) zmiany często mogą być nie widoczne, szczególnie gdy towarzyszą im świeże krwawienia. W badaniu rezonansu magnetycznego (MRI) obraz zmian nie jest charakterystyczny z powodu występowania produktów rozpadu hemosyderyny. Naczyniaki jamiste(CM) charakteryzują się dużą zmiennością w czasie. Mogą szybko się powiększać, bądź zmniejszać, rzadko pozostają bez zmian. Badacze przypuszczają, że za szybki wzrost moga odpowiadać mikrokrwawienia i rekanalizacje po powstaniu zakrzepów. Naczyniaki jamiste w $40 \%$ przypadków są objawowe i mogą powodować występowanie bólów głowy, drgawek oraz ubytków neurologicznych.

W pracy przedstawiamy przypadek niespełna 6 letniego chłopca, który po raz pierwszy trafit do Kliniki Neurologii i Rehabilitacji Dziecięcej UDSK w Białymstoku z powodu wystąpienia w 16 miesiącu życia pierwszego w życiu napadu drgawkowego o ogniskowym początku z zaburzeniami świadomości. W trakcie 5 letniej obserwacji napady padaczkowe nie powtarzały się. Utrzymano leczenie kwasem walproinowym. Mnogość i/lub lokalizacja malformacji naczyń mózgowych często uniemożliwiają podjęcie skutecznego i bezpiecznego przyczynowego leczenia zabiegowego. Napady padaczkowe u dziecka z potwierdzoną malformacją naczyń mózgowych wymagają włączenia leczenia przeciwpadaczkowego mimo dyskusyjnego związku przyczynowego napadów z anomalią.

Słowa kluczowe: naczyniaki jamiste, malformacje naczyniowe, drgawki

\section{ABSTRACT}

Cavernous hemangiomas(CM) are benignlesionsofthe hamartoma type.Their prevalence in the general population ranges from $0.4-0.8 \%$ and accounts for $15 \%$ of all vascular defects. CM incidence is estimated to be second only to developmental venous malformations taking. Most of $\mathrm{CM}$ have the characteristic of single changes. On CT changes may often not be visible, especially when accompanied by fresh bleeding. On MRI the lesion picture is characteristic due to the presence of hemosiderin break down products. $\mathrm{CM}$ are characterized by high variability over time. They can either increase or decrease rapidly, and rarely remain the same. Researchers speculate that microbleeding and recanalization after clot formation may be responsible for the rapid growth. CM are symptomatic in $40 \%$ of cases and may cause headaches, convulsions and neurological deficits. We present a case of a nearly 6 -year-old boy who was first admitted to the Department of Child Neurology and Rehabilitation UDSK in Bialystok at 16-month of age due to the occurrence of the first focal seizures with impaired awareness. During the 5-year follow-up, epileptic seizures did not repeat. Treatment with valproic acid was continued. The multiplicity and/or localization of cerebral vessels malformations often make it impossible to undertake effective and safe causal surgical treatment. Epileptic seizures in a child with confirmed cerebrovascular malformation require antiepileptic treatment despite the questionable causal relationship between seizures and the anomaly.

Key words: cavernous hemangiomas, vascular malformations, convulsions

\section{WSTĘP}

Naczyniaki jamiste(Cavernous hemangiomas-CM) to łagodne zmiany o typie hamartoma. Rozpowszechnienie ich w populacji ogólnej waha się $0,4-0,8 \%$ i stanowi ok. $15 \%$ wszystkich wad naczyniowych. W częstości występowania szacuje się, że są drugie w kolejności po rozwojowych malformacjach żylnych [1]. Większość ma charakter zmian pojedynczych, w $1 / 3$ przypadków sporadycznych i $2 / 3$ rodzinnych sa to zmiany mnogie. W badaniu CT zmiany często mogą być nie widoczne, szczególnie gdy towarzyszą im świeże krwawienia. W badaniu MRI obraz zmian jest charakterystyczny z powodu występowania produktów rozpadu hemosyderyny. Mają one różny wzór wzmacniania się po dożylnym podaniu środka kontrastują- cego, sekwencjami szczególnie przydatnymi w ich wykrywaniu są obrazy T2 oraz DWI. CM ponadto charakteryzują się dużą zmiennością w czasie. Mogą szybko się powiększać, bądź zmniejszać, rzadko pozostają bez zmian. Badacze przypuszczają, że za szybki wzrost mogą odpowiadać mikrokrwawienia i rekanalizacje po powstaniu zakrzepów [2]. Naczyniaki jamiste w $40 \%$ przypadków są objawowe i mogą powodować występowanie bólów głowy, drgawek oraz ubytków neurologicznych

\section{OPIS PRZYPADKU}

Chłopiec w wieku 1 roku i 4/12 został przyjęty do Kliniki Neurologii Dziecięcej z powodu napadu drgawkowe- 
go o ogniskowym początku z zaburzeniami świadomości. Obserwowano toniczne wyprężenie ciała, zwrot głowy w prawą stronę oraz wyprost prawej kończyny górnej, następnie drgawki początkowo prawej kończyny górnej, następnie obustronne toniczno-kloniczne. Był to pierwszy incydent drgawek w życiu dziecka. W Szpitalnym Oddziale Ratunkowym podano Diazepam doodbytniczo, następnie z uwagi na brak efektu Clonazepam dożylnie, po którym uzyskano ustąpienie napadu. Dziecko było dotychczas zdrowe. Wywiad ciążowo-okołoporodowy i rodzinny nie sugerował nieprawidłowości. Rozwój psychomotoryczny chłopca przebiegał bez odchyleń: chodził samodzielnie, po schodach raczkował lub chodzi trzymany za jedną rękę, chętnie i łatwo wspinał się po meblach. Zanim podjął próby chodzenia sylabizował, aktualnie komunikuje się gestem wskazywania palcem, nawiązuje kontakt wzrokowy, rozumie proste polecenia.

Przy przyjęciu do Kliniki pacjent był podsypiający. Z odchyleń od stanu prawidłowego w badaniu przedmiotowym stwierdzono cichy szmer nad sercem, ślad po naczyniaku płaskim na czole oraz wąskie ujście cewki moczowej. Czynność serca miarowa 124/min. W badaniu neurologicznym nie stwierdzono objawów ogniskowego uszkodzenia OUN, objawy oponowe były ujemne. W badaniach laboratoryjnych nie stwierdzono istotnych odchyleń od normy. Zapis EKG był w normie wiekowej. W zapisie EEG nie zarejestrowano zmian napadowych i zlokalizowanych. W badaniu MRI OUN opisano w górnej części lewego płata skroniowego, bocznie od rogu potylicznego oraz w prawym płacie potylicznym, przyśrodkowo obecność malformacji naczyniowych o charakterze naczyniaków jamistych(ryc. 1, ryc. 2). W celu pogłębienia diagnostyki wykonano angio-CT z fazą żylną, które potwierdziło obecność naczyniaków jamistych, ze zmianami pokrwotocznymi. Z uwagi na wysokie ryzyko powtarzania się napadów padaczkowych zdecydowano o wprowadzeniu do leczenia $\mathrm{p} /$ padaczkowego kwasu walproinowego w dawce docelowej $30 \mathrm{mg} / \mathrm{kg} /$ dobę. Następnie dziecko przekazano do Kliniki Neurochirurgii CZD celem dalszego leczenia. Z informacji zwrotnej od rodziców chłopca-odstąpiono od leczenia neurochirurgicznego z uwagi na mnogi charakter zmian. Zalecono dalszą obserwację oraz kontrolne badania obrazowe co $6 \mathrm{~m}$-cy. W trakcie pięcioletniej ambulatoryjnej obserwacji napady u chłopca nie powtarzały się. W zapisie EEG obserwowano pojawienie się zmian napadowych w postaci fal ostrych w lewej okolicy czołowo centralnej i czołowo skroniowej. Kontrolne badania MR OUN wykonywane co 6-12 miesięcy nie wykazały nowych ognisk krwawienia. W styczniu 2021 roku dziecko zostało przyjęte do Kliniki celem wykonania kolejnego kontrolnego badania rezonansu magnetycznego. W wykonanym wówczas badaniu MR opisano w lewej okolicy ciemieniowej naczyniaka jamistego z aktywnym krwawieniem (ryc.3). Ponadto ogniska niskiego sygnału w istocie białej podkorowej w prawej półkuli mózgu w płacie czołowym na sklepistości, w płacie potylicznym przystrzałkowo oraz w istocie białej przykomorowej przy trzonie komory bocznej. Dziecko ponownie przekazano do Kliniki Neurochirurgii CZD celem kwalifikacji do zabiegu operacyjnego, z którego chłopiec został zdyskwalifikowany. Dziecko zakwalifikowano do zabiegu usunięcia naczyniaka jamistego w ośrodku w Katowicach, gdzie przeprowadzono zabieg chirurgicznego usunięcia naczyniaka jamistego lewego płata ciemieniowego z uwagi na zlokalizowany w jego pobliżu ośrodek Wernickiego.

\section{DYSKUSJA}

Naczyniaki jamiste zaliczane są do wewnątrzczaszkowych malformacji naczyniowych. Oprócz naczyniaków jamistych zalicza się do nich malformacje tętniczo-żylne, żylne anomalie rozwojowe(dawniej nazywane naczyniakami żylnymi). Mogą występować w różnych częściach mózgu, a w związku z tym prowokować różne objawy neurologiczne. W badaniach autopsyjnych stwierdza się je u ok. $0,5 \%$ populacji bez korelacji z płcią. Ponad połowa $\mathrm{z}$ nich jest rozpoznawana $\mathrm{u}$ młodych dorosłych, a około $30 \%$ u dzieci. W połowie przypadków są to malformacje wrodzone,które dziedziczą się autosomalnie dominująco. Mutacje odpowiedzialne za ich powstawanie to: mutacje genów: CCM1- 7q21 na długim ramieniu chromosomu 7, CCM2-7p15- p13 na krótkim ramieniu chromosomu 7 , CCM3-3q25 na chromosomie 3 [3]. Zbudowane są z poszerzonych, cien $\neg$ kościennych kanałów i zatok naczyniowych, wyścieła $\neg$ nych śródbłonkiem, bez prawidłowego miąższu mózgu pomiędzy nimi. W zatokach następuje naprzemiennie nieregularne wykrzepianie krwi i rozpuszczanie skrze $\neg$ pów. Ściany naczyń pozbawione tkanki podporowej, mięśniówki i włókien elastycznych są słabe, co sprzyja występowaniu krwawień. Krwawienia przebiegają łagod $\neg$ nie, pod niskim ciśnieniem, często mają postać sączenia. Glej pomiędzy naczyniami i wokół naczyniaka wykazuje nasilone zmiany zwyrodnieniowe i jest przebarwiony he $\neg$ mosyderyną, produktem rozkładu hemoglobiny. Makro $\neg$ skopowo wyglądają jak guzy o nierównej powierzchni, złożone z cienkościennych jam wypełnionych krwią, po $\neg$ równywane czasami do maliny. Ich wielkość waha się od kilku milimetrów do kilku centyme $\neg$ trów. Są zwykle pojedyncze, ale mogą występować jako mnogie, szczególnie ich postać rodzinna. Naczyniaki jamiste wywierają ucisk na okoliczne obszary mózgu, a gromadząca się wokół naczyniaka hemosyde $\neg$ ryna ma drażniące oddziaływanie na neurony. Wielkość naczyniaka jamistego może się zwiększać przy utrudnie $\neg$ niu odpływu żylnego i wzroście ciśnienia żylnego, a tak $\neg$ że poprzez gromadzenie się wynaczynionej krwi. Naczy $\neg$ niaki jamiste ujawniają się napadami padaczkowymi, bólami i zawrotami głowy, objawami udaru krwotoczne $\neg$ go mózgu, wymiotami, czkawką, zmianami zachowania, zaburzeniami mowy, wzroku. Objawy te zależą od poło $\neg$ żenia wady, a także jej wielkości i charakteru krwawień. Najczęściej występującym objawem są napady padaczkowe obser $\neg$ wowane u $60 \%$ chorych, następnie postępujące zaburze $\neg$ nia neurologiczne u 50\% i skutki wytworzenia krwiaka śródmózgowego u 20\% chorych. Jednakże wg Josephson et al. 2011 5-letnie ryzyko wystąpienia napadu w naczyniakach jamistych zarówno tych z krwawieniem, jak i wykrytych przypadkowo jest znacznie mniej istotne w porównaniu do AVM(malformacji tętniczo-żylnych) z krwawieniem[3]. Jedynym skutecznym sposobem leczenia naczyniaków 
jamistych jest ich operacyjne usunięcie. W przypadkach, w których ryzyko operacyjne jest wysokie, głównie z po-wodu niekorzystnego położenia naczyniaka, takich jak położone w okoli $\neg$ cach mózgu z ciasnym nagromadzeniem ważnych czyn-nościowo struktur, jak pień mózgu, jądra podkorowe czy podwzgórze stosuje się postawę zachowawczą. Podejmowane są też próby wy $\neg$ korzystania radiochirurgii do leczenia naczyniaków jami`stych, ale nie ma dotychczas dowodów, że za pomocą tej metody można wyleczyć chorych z naczyniakiem jami $\neg$ stym albo zmniejszyć ryzyko krwawienia czy występowa $\neg$ nia objawów uszkodzenia układu nerwowego. Naczyniaki jamiste mózgu wykryte przypadkowo, bezobjawowe, zazwyczaj poddaje się obserwacji, pole-gającej na okresowych badaniach MRI OUN, co 12 miesięcy, od których można odstąpić, jeżeli wada nie zmienia się w czasie. Powiększanie się naczyniaka stanowi wskaza $\neg$ nie do podjęcia leczenia operacyjnego [4].

\section{PODSUMOWANIE}

Mnogość i/lub lokalizacja malformacji naczyń mózgowych często uniemożliwiają podjęcie skutecznego i bezpiecznego przyczynowego leczenia zabiegowego. Napady padaczkowe u dziecka $\mathrm{z}$ potwierdzoną malformacją naczyń mózgowych wymagają włączenia leczenia przeciwpadaczkowego mimo dyskusyjnego związku przyczynowego napadów z anomalią naczyniową i braku zmian napadowych w EEG. Wydaje się, że napady związane z CM można przypisać złogom hemosyderyny odkładającym się w otoczeniu naczyniaka jamistego. Leczenie farmakologiczne p/padaczkowe jest przeważnie skuteczne. Ponadto dynamiczny charakter zmian oraz ryzyko krwawienia wewnątrzczaszkowego wymagają systematycznego monitorowania stanu pacjenta i wykonywania kontrolnego badania neuroobrazowego nie tylko w przypadku nawrotu napadów lub innych objawów neurologicznych.

Ryc 1 1-badanie mr: w górnej części lewego płata skroniowego, bocznie od rogu potylicznego niejednorodny obszar, o wymiarach 17,3/9,0 mm w płaszczyźnie osiowej z niskosygnałową strefą obwodową, odpowiadający, najprawdopodobniej naczyniakowi jamistemu.

fig. 1. mr: in the upper part of the left temporal lobe, lateral to the occipital horn, a heterogeneous area, $17.3 / 9.0 \mathrm{~mm}$ in the axial plane with a low-signal peripheral zone, most likely corresponding to a cavernous hemangioma.

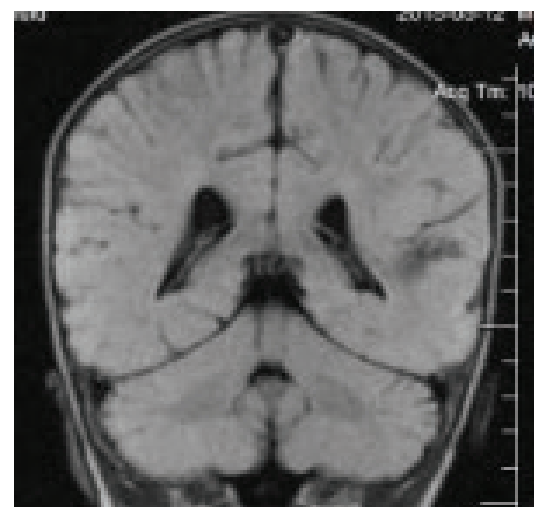

Ryc. 2 Badanie MR: Niejednorodny obszar przyśrodkowo w płacie potylicznym prawym o wymiarach $20 \times 20 \times 15 \mathrm{~mm}$ Fig. 2. MR examination: Heterogeneous medial area in the right occipital lobe with dimensions of $20 \times 20 \times 15 \mathrm{~mm}$

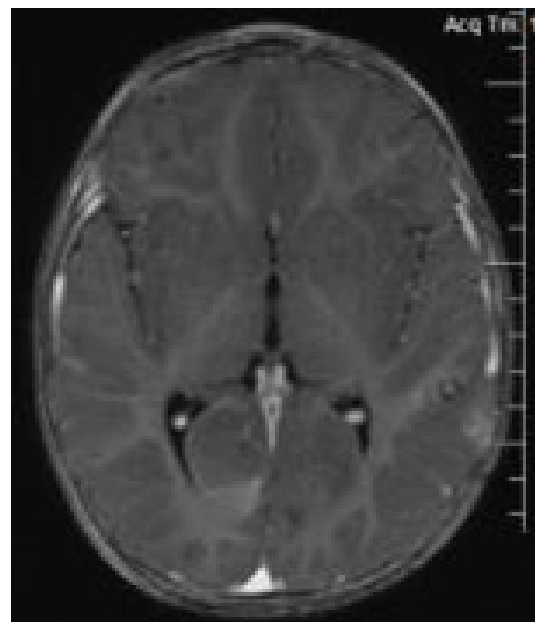

Ryc. 3 Badanie MR: W lewym płacie ciemieniowym widoczna malformacja naczyniowa, z otoczką bezsygnałową i hypointensywną - zwapnienia/złogi hemosyderyny, ze świeżym krwawieniem, o łącznych wym. ok. $20 \mathrm{~mm}$ x $20 \mathrm{~mm}$ $\mathrm{x} 15 \mathrm{~mm}$

Fig.3. MR examination: In the left parietal lobe visible vascular malformation, with signalless and hypointense sheath - calcifications / haemosiderin deposits, with fresh bleeding, total dimensions approx. $20 \mathrm{~mm} \times 20 \mathrm{~mm} \times 15 \mathrm{~mm}$

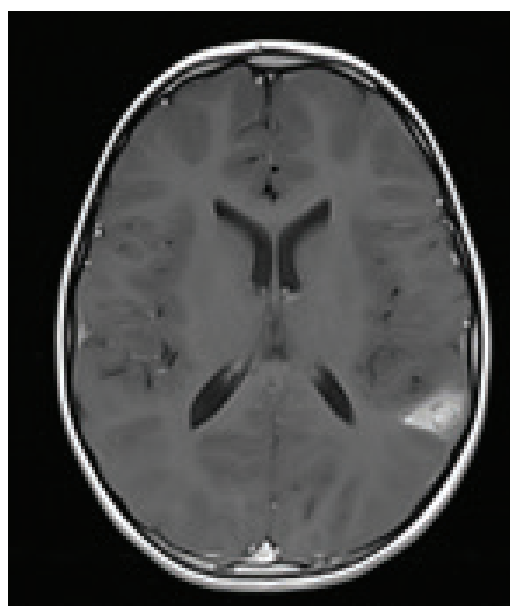

\section{PIŚMIENNICTWO}

[1] Batra S., Lin D., Recinos P., et al.: Cavernous malformations: natural history, diagnosis and treatment Nat. Rev. Neurol. 2009; 5: 659-670.

[2] Josephson C.B., Leach J.P., R Duncan R., et al.: Seizure Risk from cavernous or arteriovenous malformations, Neurology 2011; 76: 1548-1554.

[3] Felbor U., Sure U., Grimm T., et al.: Genetics of cere $\neg$ bral cavernous angioma. Zentralbl. Neurochir. 2006; 67: 110-116.

[4] Raychaudhuri R., H Huntington Batjer, A Awad I.: Intracranial cavernous angioma: a practical review of clinical and biological aspects, Surg Neurol 2005; 634:319-328.

Adres do korespondencji:

Anna Szyszko-Szwed, Klinika Neurologii i Rehabilitacji Dziecięcej, Uniwersytet Medyczny im. Ludwika Zamenhoffa Waszyngtona 17, 15-274 Białystok, szyszunia@kadrmedia.pl 